\title{
Prologue to the WISA 2008 Conference Special Edition
}

\author{
HE Jacobs* \\ Department of Civil Engineering, University of Stellenbosch, Private Bag X1, Matieland, 7602, South Africa
}

\begin{abstract}
The Water Institute of Southern Africa (WISA) held its first conference in 1989 in Cape Town. The most recent and 10 Biennial WISA Conference was held in May 2008 at Sun City, South Africa. The WISA 2008 conference theme, 'Confluence of the Water Industry' set the scene for a wide range of presentations with regards to the South African water industry and research in related fields. In keeping with the conference theme this introduction provides a confluence of papers in this journal edition. A brief description of the paper selection procedure is included and each of the papers in this edition of the journal is purposefully referenced in this coherent text.
\end{abstract}

Keywords: Water Institute of Southern Africa (WISA), introduction

\section{List of abbreviations and acronyms}

$\begin{array}{lll}\text { IWPC } & - & \text { Institute of Water Pollution Control } \\ \text { NOM } & - & \text { Natural organic matter } \\ \text { SABS } & - & \text { South African Bureau of Standards } \\ \text { WDM } & - & \text { Water demand management } \\ \text { WDS } & - & \text { Water distribution system } \\ \text { WISA } & - & \text { Water Institute of Southern Africa } \\ \text { WISA 2008 } & - & \text { The } 2008 \text { Water Institute of Southern Africa } \\ & & \text { Conference } \\ \text { WRC } & - & \text { South African Water Research Commission } \\ \text { WSA } & - & \text { Water SA (journal) }\end{array}$

\section{Introduction}

This special edition of the Water SA journal (WSA) presents selected papers based on work initially presented at the Water Institute of Southern Africa (WISA) Conference held at Sun City, South Africa, between 18 and 22 May 2008. The conference theme for 2008 was 'Confluence of the Water Industry'. When speaking of confluence, which describes a process of merging, some source or origin is implied. This is true not only of water, but also of the water industry and related institutions as a whole.

Water SA has thus far published 4 WISA Special Editions, but none have included an introduction, making this the first published introduction to a WSA WISA special edition. To mark the occasion it is deemed appropriate to include a brief history of WSA and of WISA.

\section{Origin and brief history}

\section{The Water Association of South Africa and the conference series}

The first steps towards a 'South African Water Association' were taken on 4 May 1937 in Johannesburg, at a meeting held at the Cydna Biochemical Laboratory, where it was unanimously agreed that an association would be formed with the objectives set forth on pages 13 to 15 of the Articles of the Association

\footnotetext{
* To whom all correspondence should be addressed.

甶 +2721 808 4059; fax: +271 808 4351; e-mail: hejacobs@sun.ac.za
}

of the British Institute of Sewage Purification (eWISA, 2009a). The association was at the time recognised as the South African Branch of the Institute of Sewage Purification. In 1967 the name changed to the Institute of Water Pollution Control (IWPC). Upon the disbandment of the IWPC the Water Institute of Southern Africa (WISA) was formed in 1987.

The first conference in the WISA series took place from 29 to 30 March 1989 in Cape Town (WISA, 1989) two years after the formal inception of WISA. The second was sequentially numbered and took place from 13 to 15 May 1991 in Kempton Park (WISA, 1991). However, the WISA conference papers were still published by the IWPC well after 1987. Table 1 presents a summary of the WISA conferences held to date (mainly from eWISA, 2009b; Mayne and Wheal, 2008). Two anomalies are noted in the tabulated list: two 'WISA conferences' are included in 1985 and 1987, for which information was available from WISA and the eWISA web site (eWISA, 2009b), although these pre-date the $1^{\text {st }}$ WISA Conference held in 1989; secondly, a conference took place every other year except in 1995, when a year was skipped. No explanation could be found for these anomalies when compiling this brief history and it was not considered critical to resolve the matter for the purposes of this introduction.

Since the late 1990s none of the WISA conferences have been numbered, possibly due to confusion regarding the correct enumeration procedure. However, it can now be stated with certainty that the next WISA Biennial Conference, scheduled for 2010 , will be the ' $11^{\text {th }}$ Biennial WISA Conference'.

\section{Water SA and special editions}

In 1971, only a few years after the inception of the IWPC, the South African Water Research Commission (WRC) was established in terms of the Water Research Act (Act No 34 of 1971). The Act provides for the promotion of research in connection with water affairs (RSA, 1971). The inception of the WRC was the immediate result of a period of drought in the country - the former Government considered it a matter of national interest at the time to create new knowledge and to improve the management of the country's water resources by means of research, given the perception at the time that water would be one of the most notable limitations on development in the country in the $21^{\text {st }}$ century (eWISA, 2009a).

Only 4 years after its inception the WRC started publishing a quarterly peer-reviewed journal called 'Water $S A$ ', to 


\begin{tabular}{|c|c|l|c|c|}
\hline \multicolumn{5}{|c|}{ WISA Conference history } \\
\hline Number & Year & Location & \multicolumn{2}{c|}{ Number of } \\
\cline { 3 - 5 } & & & $\begin{array}{c}\text { papers } \\
\text { presented }{ }^{\text {A }}\end{array}$ & $\begin{array}{c}\text { delegates } \\
\text { attended }\end{array}$ \\
\hline N/a ${ }^{\text {B }}$ & 1985 & Durban & 41 & N/a \\
\hline N/a ${ }^{\text {B }}$ & 1987 & Port Elizabeth & 51 & N/a \\
\hline $1^{\text {C }}$ & 1989 & Cape Town & 31 & N/a \\
\hline 2 & 1991 & Kempton Park & 50 & N/a \\
\hline 3 & 1993 & Durban & 75 & N/a \\
\hline 4 & 1996 & Port Elizabeth & 95 & N/a \\
\hline 5 & 1998 & Cape Town & 191 & N/a \\
\hline 6 & 2000 & Sun City & 180 & 575 \\
\hline 7 & 2002 & Durban & 195 & 917 \\
\hline 8 & 2004 & Cape Town & 218 & 1060 \\
\hline 9 & 2006 & Durban & 200 & 1249 \\
\hline 10 & 2008 & Sun City & 200 & \\
\hline
\end{tabular}

Notes:

A Includes poster papers (full papers required by WISA for poster presentations)

$B$ These two events were included in the eWISA/WISA data base, but are not reported as "WISA Conferences" in literature.

C This was specifically identified as being the "First WISA Conference" in the literature

disseminate research results. The first issue was published in April 1975 and the very first paper to be published in this first edition (Gebhardt, 1975) is referenced by Jacobs and Strijdom (2009) in this Special Edition. After 27 years of publishing the journal, the first 'Special Edition' of Water SA appeared in 2002, following the widely attended WISA conference in that year. A total of 7 special editions of the journal have since appeared, including this issue, averaging about one special edition per year since 2002. Four of these pertain to WISA conferences, making WISA the only conference series consecutively publishing a Special Edition since its first in 2002.

In July 2008 the WSA Editorial Board accepted a proposal to limit the publication of future Water SA special editions to a maximum of one per year.

\section{Paper selection}

The WISA 2008 organising committee required full paper submission as per a prescribed format of all accepted abstracts, for both oral and poster presentations. Following the conference all papers were published in their original form electronically (eWISA, 2009b) by WISA. The papers were not peer reviewed as part of that process.

The WISA Technical Committee was tasked to select papers for possible publication in this WSA/WISA Special Edition. These selected papers were subsequently subjected to peer review as per WSA criteria; a guest editor was appointed to guide the process along the guidelines pertaining to WSA special editions. The procedure is briefly described:

- Step 1 - Screening of oral presentations: at the conference the Chairperson of each technical session, as well as two selected delegates in the session audience, were asked to judge each presentation based on its technical content. These results were gathered by the technical committee from session Chairpersons. However, the oral presentations would not necessarily reflect the quality of the paper submitted for the conference proceedings. Also, as the Chairpersons would not necessarily be subject experts in all the fields presented during their sessions, this method of selection could not solely be relied on. Step 2 was therefore included to add value and to overcome possible subjectivity during Step 1.

- Step 2 - Screening of papers: the WISA 2008 Technical Committee proceeded independently to screen each paper (not the presentation) to identify those that were considered suitable for review. All papers identified in Step 1 and Step 2 passed to Step 3 .

- Step 3 - Filtering of papers: The remaining papers were revisited and manually filtered by the technical committee to ensure that the work was considered suitable for peerreview and possible publication in WSA and that the work had not yet been submitted for possible publication elsewhere, save the WISA presentation.

- Step 4-Ensure fair representation: the technical committee made a decision prior to selection to ensure fair representation of the different themes at the WISA 2008 conference in the selection process. In order to achieve this goal it was necessary to reduce the number of papers in the pool from Step 3 in some fields, while all papers in other under-represented fields had to be revisited again, repeating Steps 2 and 3 for these papers only.

- Step 5 - Final selection: This led to a final selected pool of papers that could potentially be peer reviewed. Every corresponding author was contacted in order to confirm that the work was, in the opinion of the authors, suitable for peerreview.

Of the 200 papers presented at WISA 2008, 22 were included in the provisional selection. Two of these were dropped from the provisional pool due to corresponding authors that could not be traced. Of the remaining 20 papers only 12 papers passed the 
review process and are included in the collection presented in this edition.

\section{Structure of this Special Edition}

Articles in this edition are grouped into the following 5 topics, included in sequential order in this edition as follows:

- Water management

- Water supply- and distribution systems

- Water treatment (including filtering)

- Water reuse

- Sanitation.

The topic headings are not provided in the journal, nor were paper titles amended to reflect these topics, because it was considered obvious from paper titles how each relates to the topics above.

This special issue is not meant to reflect the depth and breadth of the issues that were shared during the conference. However, the technical committee noted reasonable representation of papers of relatively high technical standard at the WISA 2008 conference in all these topics, save one. An acute lack of papers pertaining to sanitation and sewer systems was noted (a few of those initially selected were dropped after it was learned that they had been submitted for publication elsewhere). The WRC recently expressed their concern regarding sanitation-related research in South Africa as a whole (De Swardt and Barta, 2008).

\section{Confluence of individual papers}

The 12 selected papers are grouped under the 5 broad topics listed above and address various aspects of water, from extraction, treatment, storage, and flow via various routes to end in a polluted state, ready to be treated and reused again. In this never-ending cycle the management of water and its provision as a service to mankind could be viewed as an appropriate starting point.

\section{Water management}

Poor service provision in developing countries, and particularly the provision of water-related services, present serious challenges to urban development. De Carvalho et al. (2009) provide a method to address urban water management in a holistic manner by means of a systems approach. A composite index is presented that could be used to assess the sustainability potential of a town or city. Two Southern African urban centres, Hermanus and Maputo, were selected as initial case studies to test the applicability and validity of the index. Results demonstrate that the index could highlight areas for improvement.

South Africa relies heavily on groundwater sources, with many communities in the country entirely dependent on this unseen source. Du Plessis (2009) addresses the effective management of groundwater resources as a critical aspect to ensure sustainability, focusing on specific problems experienced with the implementation of the Langebaan Road Aquifer well field as an integrated water resource and the interaction required between the different role players. Suggestions, based on the Langebaan case study, are made regarding the different aspects to be monitored and the institutional arrangements required. The author notes that an independent monitoring committee is of utmost importance to ensure the successful management of any particular groundwater resource.
Van Dijk and Van Vuuren (2009) address the problem of evaporation from open impoundments, a notable problem locally since many impoundments in South Africa are subject to relatively high evaporation rates. The use of thermal mixing by means of compressed air appears to have important potential for evaporation suppression in deep reservoirs. The authors propose a methodology to reduce evaporation losses from open-water impoundments involving the destratification of the water body using a bubble plume operated with relatively low energy input to reduce surface water temperatures, with a subsequent reduction in evaporation. Evaporation suppression of as high as 30\% has been achieved in some case studies elsewhere. The design of an artificial destratification system still needs further investigation.

In South Africa (and its neighbours) water storage dams are commonly located great distances away from large urban demand centres for various reasons, mainly to provide higher yield. Provided the dam has a narrow basin with favourable storage volume to surface area ratio as well as lower regional evaporation rates, water loss through evaporation could be reduced substantially. Gauteng Province is the industrial heartland of South Africa and is one of the few large urbanised areas in the world that is not located adjacent to a major source of water. The area relies heavily on large inter-basin water transfer schemes to transfer water from neighbouring river basins into the Vaal River basin. The water transfer schemes associated with the Vaal River basin are large by international standards and this water resource system is one of the most complex and integrated anywhere in the world. McKenzie and Wegelin (2009) address the potential for reducing the growth in demand through water conservation and water demand management (WDM) measures. From the most recent investigations it is clear that WDM is no longer considered a possible option, but rather a necessity that must be implemented as a matter of urgency. In this regard, several of the large municipalities in Gauteng have commenced with the implementation of various WDM interventions, some of which are already in operation and showing significant savings. The paper underlines the need for WDM in Gauteng and provides details of the latest investigations into the potential savings that can be achieved. Some of the key problems that are hampering the implementation of WDM interventions in Gauteng are discussed and the measures taken to overcome these difficulties are explained. The study also highlights the benefits that can be obtained from a potent web-based data acquisition system which is already operational in several parts of Gauteng.

\section{Water distribution systems}

At the end point of any water distribution system (WDS) is a device of some sort where water is ejected from the pressurised supply system to atmospheric pressure, typically a device located inside a building where water is needed by a consumer. Highquality devices, termed plumbing components by Lobanga et al. (2009), are essential to ensure the efficient and safe supply of water, and to minimise water losses in buildings. South African legislation requires that all plumbing components installed comply with particular standards set by the South African Bureau of Standards (SABS). Water services authorities are responsible for enforcing this legislation, and are allowed to set their own additional requirements for plumbing components. A study by Lobanga et al. (ibid.) investigated the extent of non-compliant plumbing components used in South Africa and concludes that compliance is roughly $50 \%$. This points to a huge problem that 
might have dire consequences for the future of effective water use and water leakage in South Africa. A worrying finding is that the level of non-compliance seems to be particularly prevalent in low-cost housing developments. The main reasons for the low levels of compliance are considered to be a lack of enforcement at local government level and the fact that legislation does not prohibit the import and sale of non-compliant components. The paper makes a number of recommendations for improving the situation. The situation is unfortunately made worse by unwanted high pressures in WDSs, particularly in low-cost areas where such high pressures might not be needed.

In some cases such high pressures are the result of stringent design criteria, perhaps too stringent for some applications. Jacobs and Strijdom (2009) investigate minimum residual pressure as design criterion for South African water distribution systems. The South African civil engineering fraternity has grown to accept $24 \mathrm{~m}$ as the design criterion for minimum residual pressure in water distribution systems. The researchers analysed hydraulic models to identify the minimum residual pressures currently expected. The results show that about $20 \%$ of model nodes in the distribution systems analysed have pressures below $24 \mathrm{~m}$, while pressures below $14 \mathrm{~m}$ are not uncommon. A new guideline for minimum residual pressure is presented. The authors note that a physical lower limit of about $10 \mathrm{~m}$ water pressure is determined by appliance specifications. A limitation of the study is the fact that this relatively common occurrence of low pressures under modelled peak demand was not confirmed by measuring water distribution pressures in practice.

Water quality in the WDS is perhaps a more critical aspect than the provision of 'sufficient pressure'. Verberk et al. (2009) note that particles in the distribution system play an important role in the perception of drinking water quality, particularly in association with discolouration. In The Netherlands the water quality in the distribution system is traditionally monitored by turbidity measurements. However, turbidity is hard to quantify. In this paper the value of on-line particle counting is discussed and analysed. The authors note that it is possible to identify various sources of particles in a distribution network by using online particle counters and pre-concentration methods. The overall conclusion of the authors is that on-line particle counters, in combination with the pre-concentration methods, are very effective and useful tools in understanding the water quality processes in WDSs.

\section{Water treatment}

Natural organic matter (NOM) occurs in all natural water sources when animal and plant material breaks down. In a study by Nkambule et al. (2009) the NOM content of the raw water from the Vaalkop Water Treatment Plant was characterised after fractionation on ion-exchange resins. Fractionation at different $\mathrm{pH}$ resulted in the isolation of a neutral, a basic and an acidic component of either predominantly hydrophobic or hydrophilic NOM. In addition, NOM from three open water bodies in Johannesburg were evaluated in the same manner. As expected, NOM from all water sources was predominantly hydrophobic. Each of the six isolated NOM fractions was percolated through synthetic cyclodextrin polyurethanes to determine the extent to which the polymers could remove NOM from the water. The hydrophobic basic fraction and the hydrophilic acid fraction were most efficiently removed. The remaining fractions were not much affected by the polymer treatment.

Mofokeng et al. (2009) investigated the full-scale singlestage tertiary nitrifying trickling filter at the Citrusdal waste- water treatment plant. The filter provides for external nitrification of unclarified effluent from the facultative aerobic lagoon in order to meet standard effluent ammonia concentration requirements. The apparent ammonia nitrification rate of the filter was sensitive to particulate organic loading rates which were predominantly in the form of algae. Installation of forced air ventilation fans improved the nitrification efficiency from $15 \%$ to $43 \%$. An increase in hydraulic loading rate by effluent recirculation significantly improved the apparent ammonia nitrification rate, eradicated filter flies and decreased the prevalence of nematodes. An ammonia-removal efficiency of approximately $71 \%$ was achieved. Profile samples were collected and indicated poor biofilm activity and prevalence of motile algae during the cold and rainy winter period. Under low hydraulic loading rates and warmer temperatures a dominance of filter flies and fly larvae were observed. The results were compared to controlled laboratory studies which, in conformity with full-scale, were found to be sensitive to hydraulic loading conditions.

\section{Water reuse and sanitation}

Wastewater reuse is becoming increasingly important to supplement drinking-water supply needs and to reduce costs in many communities around the world. However, wastewater reuse can result in a potential transmission route for infectious agents. Rietveld et al. (2009) assessed Cryptosporidium in a treatment plant for the production of drinking water from wastewater effluent and compared findings to an existing drinking water treatment plant in Amsterdam, The Netherlands. The assessment was done using the Monte-Carlo simulation and probability density functions to determine the occurrence of Cryptosporidium in raw surface water and wastewater effluent and the removal in different treatment steps. From the research conducted, it was concluded that under normal conditions, drinking water that meets Dutch drinking water quality standards could also be produced from treated wastewater treatment effluent. However, extra redundancy should be built in to meet the standards under extreme operating conditions.

One method of supplying the reused water to consumers could be via a dual water supply system, which comprises separate pipes that supply different water qualities to the end consumer, for example potable and non-potable water. The application of dual water reticulation systems in South Africa has been limited for various reasons. Ilemobade et al. (2009) developed a decision-making framework, using robust criteria, for assessing the viability of implementing dual systems in South Africa. As part of the work questionnaires were developed to gain inputs, focusing on 7 key issues, namely public health and safety, economics, technical feasibility, legislation/regulations and guidelines, organisational capacity, social acceptance, and public education. The so-called 'triple bottom line of sustainability' (economic, environmental and social aspects) provided structure to the framework and was utilised in the assessment of the different criteria.

Pit latrines are a common alternative in South Africa to 'conventional' waterborne sewers. The functioning of pit latrines is crucial in view of the large numbers of these sanitation devices installed locally. There is considerable national interest in the use of commercial microbially derived products for controlling the rate of accumulation of the contents of pit latrines. Manufacturers claim that some of these products can reduce accumulation rates, prevent the pit from ever filling up, or may even result in decreases in pit contents volume. Foxon et al. (2009) provide the first scientific publication to investigate these claims. 
Reproducible laboratory tests were designed to quantify the effect of commercial pit-latrine additive products. Protocols were developed and tested on a range of different commercial products sold for their ability to control the rate of accumulation of pit- latrine contents. The effect of commercial additives on mass loss from pit-latrine sludge was compared to mass loss from similar units subjected to no treatment and treatment with water. The study concluded that treatment with commercial pitlatrine additives did not accelerate the rate of biodegradation or mass loss within pit-latrine contents.

\section{Acknowledgements}

The author (and Guest Editor of this edition) would like to express his sincere thanks to Wallace Mayne (formerly WISA), Melissa Wheal (WISA), Willem Botes (eWISA/WAMTech) and Ingrid Buchan (WRC/WSA) for input to this introduction as well as to all the authors and reviewers of the individual papers who contributed to make this special issue possible.

\section{References}

DE CARVALHO SCP, CARDEN KJ and ARMITAGE NP (2009) Application of a sustainability index for integrated urban water management in Southern African cities: Case study comparison - Maputo and Hermanus. Water SA 35 (2) 144-151.

DE SWARDT BW and BARTA B (2008) A First Order National Audit of Sewer Reticulation Issues. A report to the South African Water Research Commission by Industrial and Urban Infrastructure (Pty) Ltd. WRC Report No. 1671/1/08. Water Research Commission, Pretoria, South Africa.

DU PLESSIS JA (2009) Managing the unseen: Langebaan road aquifer system. Water SA 35 (2) 152-157.

eWISA (2009a) http://www.ewisa.co.za/frame.aspx?url=misc/WaterHistory/default.htm (Accessed 2 December 2008).

eWISA (2009b) http://www.ewisa.co.za/frame.aspx?url= $/ \mathrm{misc} /$ WISAConf/default.htm (Accessed 2 December 2008).

FOXON KM, MKHIZE S, REDDY M and BUCKLEY CA (2009) Laboratory protocols for testing the efficacy of commercial pit latrine additives. Water SA 35 (2) 228-235.
GEBHARDT DS (1975) The effects of pressure on domestic water supply including observations on the effect of limited garden-watering restrictions during a period of high demand. Water $S A 1$ (1) 3-8.

ILEMOBADE AA, ADEWUMI JR and VAN ZYL JE (2009) Framework for assessing the viability of implementing dual water reticulation systems in South Africa. Water SA 35 (2) 216-227.

JACOBS HE and STRIJDOM JL (2009) Evaluation of minimum residual pressure as design criterion for South African water distribution systems. Water SA 35 (2) 183-191.

LOBANGA KP, VAN ZYL JE and ILEMOBADE AA (2009) The extent of non-compliant plumbing components used in South Africa. Water SA 35 (2) 175-182.

MAYNE W and WHEAL M (2008) Personal communication with the then WISA Chief Executive and WISA administrative staff, 9 December 2008 .

MCKENZIE RS and WEGELIN W (2009) Challenges with the implementation of water demand management initiatives in Gauteng Province. Water SA 35 (2) 168-174.

MOFOKENG T, MULLER AW, WENTZEL MC and EKAMA GA (2009) Full-scale trials of external nitrification on plastic media nitrifying trickling filter. Water SA 35 (2) 204-210.

NKAMBULE TI, KRAUSE RWM, MAMBA BB and HAARHOFF J (2009) Characterization of natural organic matter (NOM) and its removal using cyclodextrin polyurethanes. Water SA 35 (2) 200203.

REPUBLIC OF SOUTH AFRICA (1971) Water Research Act. Act No. 34 of 1971. Statutes of the Republic of South Africa. Pretoria, South Africa.

RIETVELD LC, MEIJER L, SMEETS PWMH and VAN DER HOEK JP (2009) Assessment of Cryptosporidium in wastewater reuse for drinking water purposes: A case study for the city of Amsterdam. Water SA 35 (2) 211-215.

VAN DIJK M and VAN VUUREN SJ (2009) Destratification induced by bubble plumes as a means to reduce evaporation from open impoundments. Water SA 35 (2) 158-167.

VERBERK JQJC, VREEBURG JHG, RIETVELD LC and VAN DIJK JC (2009) Particulate fingerprinting of water quality in the distribution system. Water SA 35 (2) 192-199.

WISA (1989) First Biennial WISA Conference and Exhibition: Papers (3 volumes). Cape Town, 29-30 March 1989. Published by the Institute of Water Pollution Control (South African branch), Parklands, South Africa.

WISA (1991) Proc. $2^{\text {nd }}$ Bienn. WISA Conf. 13-15 May 1991, Kempton Park, South Africa. Published by the Institute of Water Pollution Control (South African branch), Parklands, South Africa. 